\title{
An Evacuation Efficiency Contribution Index of Public Building's Space Models
}

\author{
Hong $\mathrm{Xu}^{1}$ \\ ${ }^{1}$ College of Urban Construction, \\ Wuhan University of Science and Technology, \\ Wuhan, China, 430065, \\ xuhong@wust.edu.cn
}

\begin{abstract}
Evacuation efficiency of public buildings are closely related to their space structures. However, there is lacking of correlating analysis methods of both of them, which lead to the ignoring of evacuation efficiency contribution not able to support the space structure design of public buildings. In this paper, we proposed a concept of hierarchical organization map of public buildings, then proposed a quantitative measurement method of evacuation efficiency contribution for space structure combination models of public building. This paper developed an prototype system to implement this method, and testing of 7 building design plans were shown to validity the proposed method. This method can make up the lacking of quantitative measurement approach of evacuation efficiency, which can provide scientific reference for architecture design in order to meet the requirements of evacuation performance of public buildings.
\end{abstract}

Keywords: Public building evacuation; Building Space; Combination model; contribution index

\section{Introduction}

Rapid urbanization has dramatically changed the public buildings and urban form [1]. Faced with an increasing number of uncertain safety factors, there is a growing emphasis on the evacuation efficiency of public buildings. Evacuation efficiency of public buildings has a very close relationship of space layout in it. It need to achieve a harmonization of functions and evacuation needs in a scientific and rational manner, which should be on base of public building space analysis theory and methods. This theory is also a very important, urgent research questions for in the field of building studies.

The connection between architectural space units is an important concerns by architects and researchers. There are some architectural space combination fuzziness and scale resistance, which are difficult to be defined accurately. Some scholars conducted the research of building space combinations, such as, the typical form of space combinations $[2,3]$, the space division from a viewpoint of behavior in the space environment [4], including: parallel, centralized, linear space, radiant, cluster, grid-style, courtyard and other space combined models. These space can also be combined with nature of functional requirements, volume size, traffic routes and other factors. These space can be used to create a complex architecture by separating and dividing, convergence with the transition, comparing with the change in the axis, repeating with reproduction, guidance and hinted penetration, circulation, order and sequence techniques and so on. These studies focused on spatial form [5], the function [6], the behavior of [7], and even space integration [8]. In the aspect of evacuation of building space, Zheng summarized all building evacuation simulation methods [9]. Other scholars carried out some simulated evacuations of architectural space [10], efficiency [11], impact rule [12], the engineering design [13], etc. However, the research community lacks some quantitative and analytical tools to assess the efficiency of the effective contribution of the evacuation. Xu [14] studied the combination modes of public building space, and research the differences of efficiency contribution of these modes. This paper focuses on the efficiency contribution of public buildings by proposing an evacuation contribution index, to make up lacking of quantitative assessment tools for architectural design.

\section{Proposed index}

\subsection{Hierarchical organization map of public building space}

Public building space combination mode determines the evacuation skeleton path in the evacuation process, affecting the overall output of the evacuation efficiency. And a single combination determines the way of evacuation with a fixed dynamic aggregation manner, affecting evacuees initial routing decision. Both of them are very important for the evacuation process. In order to analyze the effects of different space combination model on evacuation efficiency, we propose a hierarchical organization map of public building space (Figure 1) concept, which is defined as follows:

$G=\left\{G^{1}\right\}=\left\{\left\{G_{1}^{2}, G_{2}^{2}, \ldots G_{i}^{2}, \ldots, G_{n}^{2}\right\}\right.$, 


$$
\begin{aligned}
& \left.C G^{2}\left(G_{1}^{2}, G_{2}^{2}, \ldots G_{i}^{2}, \ldots, G_{n}^{2}\right)\right\} \\
& =\left\{\left\{\left\{\ldots\left\{G_{i 1}^{3}, G_{i 2}^{3}, \ldots, G_{i m}^{3}\right\},\right.\right.\right. \\
& \left.\left.\left.C G_{i}^{3}\left(G_{i 1}^{3}, G_{i 2}^{3}, \ldots, G_{i m}^{3}\right)\right\}, \ldots\right\}, C G^{2}\left(G_{1}^{2}, G_{2}^{2}, \ldots G_{i}^{2}, \ldots, G_{n}^{2}\right)\right\}=\ldots
\end{aligned}
$$

(1)

$$
\begin{aligned}
G_{i}^{k}= & \left\{\left\{G_{1}^{k+1}, G_{i}^{k+1}, \ldots G_{i}^{k+1}, \ldots, G_{n}^{k+1}\right\},\right. \\
C & \left.G^{k}\left(G_{1}^{k+1}, G_{i}^{k+1}, \ldots G_{i}^{k+1}, \ldots, G_{n}^{k+1}\right)\right\} \\
G^{k}= & \left(V^{k}, E^{k}\right)=\left\{\left\{v_{1}, v_{2}, \ldots, v_{n^{k}}\right\}\right. \\
& \left.\left\{e_{1}, e_{2}, \ldots, e_{m^{k}}\right\}\right\} \\
C G^{k}= & \left(C V^{k}, C E^{k}\right)=\left\{\left\{c v_{1}, c v_{2}, \ldots, c v_{n^{k}}\right\}\right. \\
& \left.\left\{c e_{1}, c e_{2}, \ldots, c e_{m^{k}}\right\}\right\}
\end{aligned}
$$

where $v$ is the node in one hierarchy map, which represents a unit abstracted from the low level of hierarchy map; $e$ is the vertex in a hierarchy map, which represents the connection relationship between different nodes; $c v$ is the sub-map of same hierarchy map, for example the node in hierarchy $\mathrm{K}$ in figure 1 ; ce means the logical connection relationship between sub-maps, for example the edge in hierarchy $\mathrm{K}$ in figure 1 。 The node in a high-level hierarchy represent a sub-map of lower-level hierarchy map consisting of nodes. These nodes make up a individual space combination model.

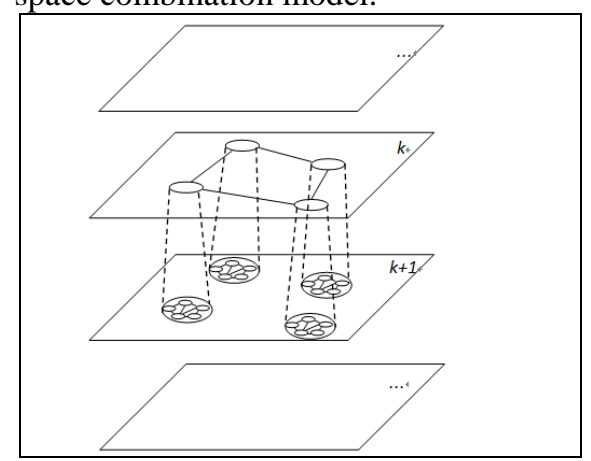

Fig. 1: Hierarchical organization map of public building space.

This hierarchical organization map of public building space has several characteristics, such as relative independence of spatial expression of public buildings, evacuated hierarchy of public building space, the importance differences of public building space, etc. This map is a basic organization to analyze the contribution index in this paper.

\subsection{Evacuation contribution index}

This paper presents a concept of evacuation efficiency contribution index to describe the relative contribution of the different space combinations. In general, for a particular space, each individual was evacuated with the shortest time, the shortest path, the more evacuated number of individuals, then the efficiency contribution of this space is higher. Based on this concept, we define evacuation contribution index (ECI) as follows:

$$
\begin{aligned}
\Phi_{G}\left(G_{i}^{1}\right) & =\sum_{j \in G_{i}^{0}}\left(G_{j}^{2}\right)=\ldots \\
& =\sum \sum \ldots \sum_{l \in G_{i}^{k}} \Phi_{G}\left(G_{l}^{k}\right) \\
\Phi_{G}\left(G_{l}^{k}\right) & =\sum_{j \in{ }_{n} k} f\left(v_{j}\right) / \Delta T\left(G_{l}^{k}\right) \\
f\left(v_{j} k\right. & =\sum_{j \in \bar{P}_{i}}\left(\frac{\operatorname{Dist}\left(p_{j}, v_{j} k\right)}{\operatorname{Length}\left(v_{j^{k}}\right)} \times \frac{\varphi}{T\left(p_{j}, v_{j} k\right.}\right)
\end{aligned}
$$

where $G$ is the hierarchical organization map of public building space. $k$ is the maximum hierarchy level, $\Phi_{G}\left(G_{l}^{k}\right)$ is the Evacuation contribution index of $G_{l}^{k}$, $\Delta T\left(G_{l}^{k}\right)$ is the evacuation time period of $G_{l}^{k}, \operatorname{Dist}\left(p_{j}, v_{j}{ }_{j}\right)$ is the trajectory length of individual $p_{j}$ in building unit $v_{j k} ; T\left(p_{j}, v_{j}\right)$ is the activity time of individual $p_{j}$ in building unit $v_{j k} ; \operatorname{Length}\left(v_{j^{k}}\right)$ is the length of building unit $v_{j k}$ along the trajectory, $\varphi$ is the parameter, $f\left(v_{j k}\right)$ the efficiency contribution index value of $v_{j}$.

\section{Experiments and analysis}

This paper developed an evacuation simulation prototype system (Fig.2) based on $\mathrm{C}++$ language, and some tools including Qt GUI, and Ggnuplot.

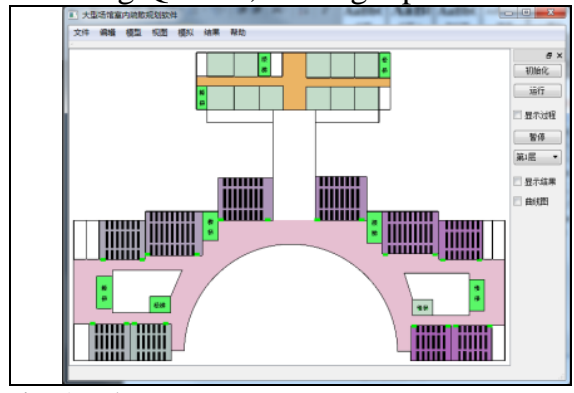

Fig. 2: The prototype system. 


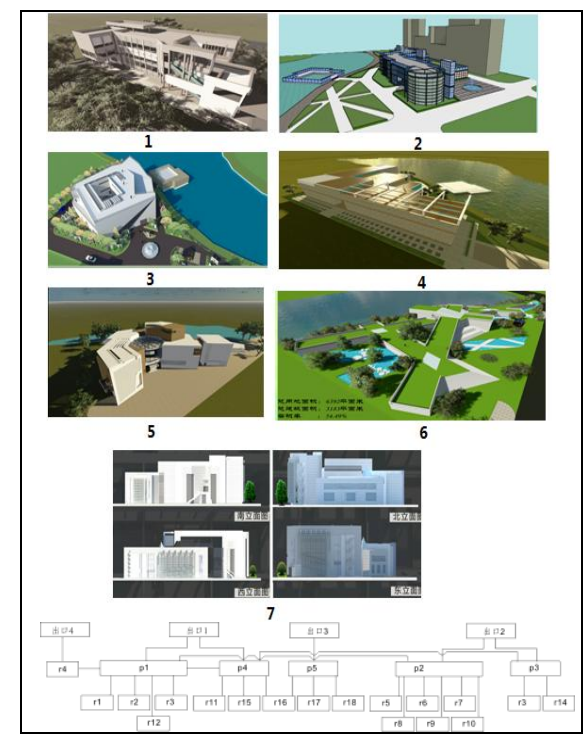

Fig. 3: The building design plans, and a hierarchical organization map of public building space in plan \#2.

Using this prototype system, the paper analyzed against seven architectural exhibition designs, all of them are under a same design specifications, so they can be compared each other. Figure 3 lists seven architecture design plans, and a hierarchical organization map of public building space in plan \#2.

Figure 4 shows the evacuation curve of seven architectural design plans. As can be seen, compared results of the evacuation efficiency is: plan \#3> plan \#7> plan \#1> plan \#4> plan \#2> plan \#6> plan \#5. plan \#3 and 7 have obvious advantages, they have a high efficiency. For example, in the first 30 seconds, plan \#2 has a very high evacuation efficiency. plan \#5 and 6 have a disadvantage of low efficiency. Plan\# 2 has a high evacuation efficiency in first 30 seconds, but followed with a slow evacuation efficiency. Plan\# 4 has a low efficiency in first 52 seconds, but after that, it has a good efficiency. Plan\# 5 always has a low efficiency performance, Plan\#4 and 6 race in the before and after 52 seconds but they are approximate on the whole.

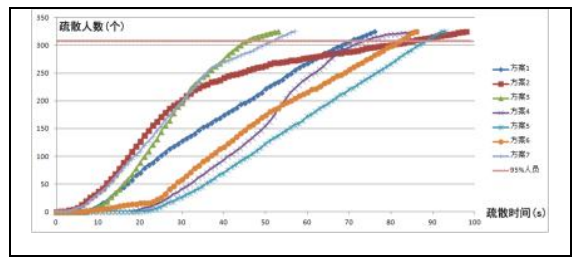

Fig. 4: The building design plans, and a hierarchical organization map of public building space in plan \#2.

Figure 5 and 6 shows ECI values of plan \#1-7. This paper discuss them as follows:

\# 1: The plan consists of three main parts: p1, p2, p3 areas. They are linear combination model, the ECI of these areas are 3.488277(14.95\%), 3.668355 (29.35\%), 12.98834 $(55.70 \%)$.

\# 2: The plan consists of five main parts: p1-p5 areas. They are linear combination model, the ECI of these three areas

are 12.76764(37.31\%),5.068523(14.81\%),2.498229(7.30\%),6.2 72746(18.33\%),7.613017(22.25\%),3.488277(14.95\%),3.66 $8355(29.35 \%), 12.98834(55.70 \%)$.

\# 3: The plan consists of centralized mode (p1 and p3) and linear model (p2), their ECI values are: 21.02347, $8.859732,4.77401$. The contribution of centralized mode is $25.79748(=21.02347+4.77401)(74.44 \%)$, evacuation efficiency of the linear spatial patterns is $8.859732(25.56 \%)$.

\# 4: The plan includes a centralized space (p1), and linear space (p2, p3, p4). Their ECI values are 14.93906, $8.68651,9.155914,5.87792$. The ECI of centralized space is $14.93906(38.64 \%)$, while ECI of linear space is $23.72034(=8.68651+5.87792+9.155914)(61.36 \%)$.

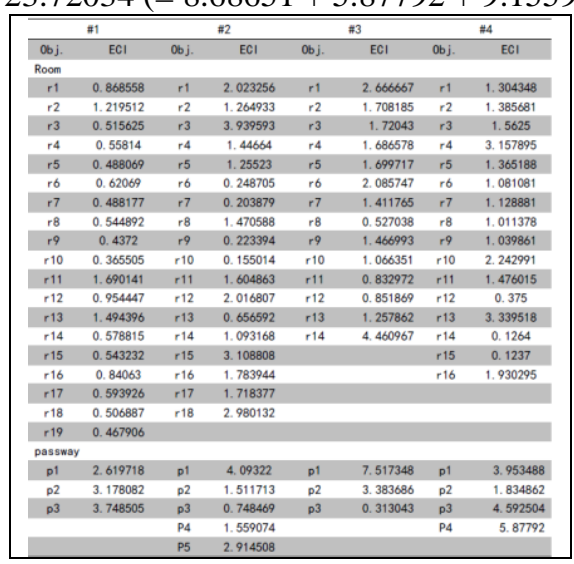

Fig. 5: The ECI values for plans \#1-4.

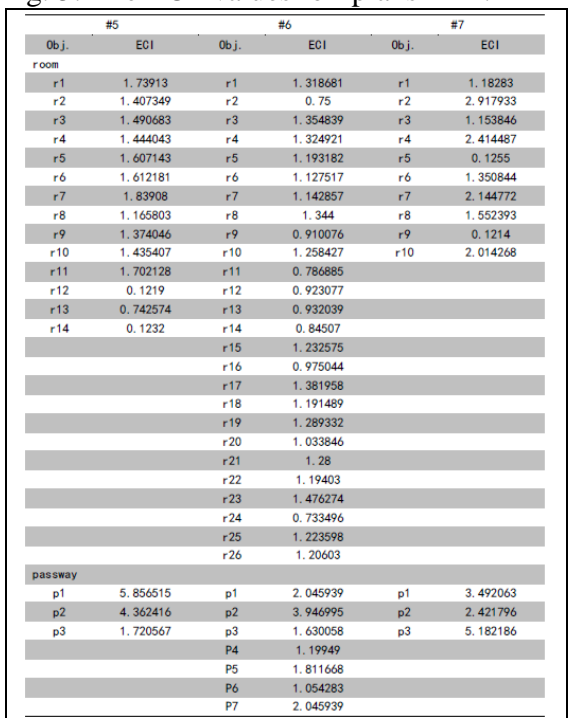

Fig. 6: The ECI values for plans \#5-7.

\#5: The plan includes radiant (p1 and p2) and linear space (p3). Their ECI values are 16.99613, 5.10499, 7.39795. The ECI of radiant space is $22.10112(=16.99613+5.10499)$ (74.92\%), the ECI of linear space is $7.39795(25.08 \%)$ 。

\#6: The plan consists concentrated space (p1, p6), and linear space (p2-5 and p7). Their ECI are 5.503194 (13.27\%), 4.580155 (11.04\%), 7.412935 (17.87\%), 6.89418 $(16.62 \%), \quad 6.936172 \quad(16.72 \%), 6.495469 \quad(15.66 \%)$, 
$3.655011(8.81 \%)$. The ECI sum of the concentration space is $11.99866(28.93 \%)$, and the sum of linear space $29.47845(71.07 \%)$.

\#7: This plan includes two centralized space(p1-2,p3). Their ECI values are 10.12731 (38.50\%), 3.815642 (14.50\%), $12.36446(47 \%) . \mathrm{p} 1$ and p2 form a centralized space which contributes $13.94296(53 \%)$ while p3 is $12.36446(47 \%)$.

\section{CONCLUSIONS}

These analysis proved the effectiveness of the proposed index, which provides a useful method to measure the evacuation contribution of public building spaces, and can be used to optimize building design plan when considering evacuation efficiency.

Acknowledgements: I would like to thanks Wang Luyao, Liu Ziyuan, Ma wenjuan, Ni Jiming, Qi Qige, Lu Ting, Xu Yuanfang for their design works.

\section{References}

[1] Qi, K., 2009. Space, Time, Architecture. Science China Series E, 39(5), 821-824.

[2] Liu, Y., , 1998. Building space's form structure, meaning and combination. Tianjin: Tianjin science and technology press.

[3] Peng, Y., 1998. Building space combinations. Beijing: China building press.

[4] Li, Z. and Wang, Y. 2009. Building space environment and behaviors. Wuhan:Huazhong University of Science and Technology Press.

[5] Besserud, K., Katz, N., Beghini, A, 2013. Structural Emergence: Architectural and Structural Design Collaboration at SOM. Architectural Design 83(2): 48-55.

[6] Peters, B. 2013. Computation Works: The Building of Algorithmic Thought. Architectural Design 83(2): 8-15.
[7] Suter, G., 2013. Structure and spatial consistency of network-based space layouts for building and product design. Computer-Aided Design 45(8-9): 1108-1127.

[8] Yao, C., 2014. Brief Discussion on Design Integration of Central Urban District Renewal. Architecture science, 30(6):49-54.

[9] Zheng X.P., Zhong T.k.,Liu M.T., 2009. Modeling crowd evacuation of a building based on seven methodological approaches. Building and Environment, 2009, 44: 437-445

[10] Rüppel, U., Schatz, K., 2011. Designing a BIMbased serious game for fire safety evacuation simulations. Advanced Engineering Informatics 25(4): 600611.

[11] Bian Y., Mei P., Lu S., 2011. An analysis of evacuation efficiency of high-rise building based on fuzzy analytic hierarchy process. Fire safety science,20(4),185-192.

[12] Li J., Hu C. 2014. Influence of crow density on movement speed on different egress pahts, Architecture science,,30(8):122-129.

[13] Zheng B. Ran H., Sun, L.2014. Engineering design methods of crowd intelligent evacuation guidance system in building fire. Architecture science,30(7):98102.

[14] Xu. H., 2013. The Evacuation Contribution Analysis of Different Space Combination Modes in Public Buildings. Doctoral dissertation of Wuhan University.

[15] FANG Z.X., LI Q.Q., LI Q.P., HAN L. D., WANG D., 2011. A Proposed Pedestrian Waiting-Time Model for Improving Space-Time Use Efficiency in Stadium Evacuation Scenarios. Building and Environment, 46(9): 1774-1784.

[16] FANG Z. X., LI Q.P., LI Q.Q., Han L. D., SHAW S.-L., 2013. A space-time efficiency model for optimizing intra-intersection vehicle-pedestrian evacuation movements. Transportation Research Part C: Emerging Technologies, 31, 112-130. 